\title{
JUVENILE MYELOMONOCYTIC LEUKEMIA AND OTHER MYELODYSPLASTIC/MYELOPROLIFERATIVE NEOPLASMS
}

\author{
Neysimelia Costa Villela ${ }^{1}$, Roseane Vasconcelos Gouveia ${ }^{2}$, Simone de Castro Resende Franco ${ }^{3}$, \\ Gustavo Zamperlini ${ }^{2}$, Patrícia Shimoda Ikeuti ${ }^{4}$, Luiz Fernando Lopes ${ }^{1}$ \\ 1. Barretos Cancer Hospital, Barretos, SP, Brazil. \\ 2. Hospital Samaritano, São Paulo, SP, Brazil \\ 3. Hospital da Criança de Brasília José de Alencar. Brasília, DF, Brazil \\ 4. Instituto de Oncologia Pediátrica IOP/GRAACC/UNIFESP, São Paulo, SP, Brazil.
}

Correspondence to: ncvillela@hotmail.com

\section{JUVENILE MYELOMONOCYTIC LEUKEMIA (JMML)}

It is a clonal hematopoietic disorder that usually occurs in early childhood, characterized by hyperactivation of the RAS signaling pathway. About $90 \%$ of patients have mutations in 1 of 5 genes (PTPN11, NRAS, KRAS, NF1, CBL) that define genetically and clinically distinct subtypes of the disease, with a highly variable clinical course. ${ }^{1,2}$

Patients with somatic PTPN11 mutations generally have a rapidly fatal outcome if they are not submitted to allogeneic hematopoietic stem cell transplantation (HSCT). The relapse rate after HSCT is significantly higher in these patients, when compared to other genetic subtypes. Likewise, JMML is also fatal in the absence of HSCT in patients with neurofibromatosis type 1 (NF1). Patients with somatic mutation in KRAS generally present clinically very aggressive disease, promptly requiring $\mathrm{HSCT}$, but the relapse rate after HSCT is relatively low. JMML associated with somatic NRAS mutation shows great clinical diversity, some patients have a disease that slowly regresses in the absence of HSCT, while others have an aggressive disease, with a high rate of relapse after HSCT (usually older children, with high levels HbF). Most children with $\mathrm{CBL}$ germline mutation have self-limiting disease and observation without therapy is generally recommended. In children with JMML phenotype without an identified mutation of the RAS pathway, HSCT is indicated, but it is necessary to exclude other rare myeloproliferative diseases, acute leukemia and non-malignant diseases. ${ }^{1-3}$

Patients with Noonan Syndrome (PTPN11 germline mutation or another gene in the RAS pathway) may have a transient myeloproliferative disorder, usually in the first months of life, with clinical characteristics indistinguishable from LMMJ. In these cases, HSCT is not indicated. ${ }^{3,4}$

The results of HSCT in patients with JMML have progressively improved over time. In the study including the largest number of JMML patients undergoing related and unrelated allogeneic HSCT, the probability of disease-free survival was $52 \%$. Relapse was the main cause of treatment failure, with an incidence of $35 \% .{ }^{1,5}$ The use of umbilical cord blood proved to be a viable option. 6 Although still experimental in the treatment of JMML, haploidentical HSCT can be considered for patients without a compatible donor. ${ }^{1,7}$

The classic conditioning regimen consists of busulfan, cyclophosphamide and melphalan..$^{5,8}$ The Japanese group uses busulfan, fludarabine and melphalan, with similar results. ${ }^{9}$

In order to optimize the effect of the graft against leukemia, a less intensive GvHD prophylaxis is recommended for patients with a higher risk of relapse (patients with NF1, somatic mutation of PTPN11 and NRAS, minimum 4 years of age or $>20 \%$ blasts in the bone marrow).

Pre-transplant therapy is still a matter of controversy. Conventional chemotherapy is generally not associated with durable responses, but the use of lowdose 6-mercaptopurine and/or cytarabine can be effective in reducing leukocytosis and spleen size.1,10 Azacitidine as a bridge until transplantation has been shown to be a promising option. ${ }^{11,12}$ The European group (EWOG-MDS) is currently conducting a multicenter phase II study that aims to prospectively assess the rate of complete or partial clinical remission after three cycles of pre-HSCT azacitidine in newly diagnosed JMML patients. ${ }^{13}$ 
A second HSCT can rescue more than a third of children who experience relapse after the first transplantation, while donor lymphocyte infusion (DLI) appears to be ineffective. ${ }^{1}$

Chronic Myelomonocytic Leukemia (CMML) and Atypical Chronic Myeloid Leukemia (negative Bcr-Abl aCML)

CMML is extremely rare in children. In the pediatric classification proposed by Hasle, in 2003, the term
CMML was included only for cases secondary to previous chemotherapy. ${ }^{14-16}$

Atypical CML is even more rare in children than in adults. Of the few cases reported in childhood, some have failed to meet the diagnostic criteria. Due to its rarity and heterogeneity, there is no consensus on treatment, however, due to the unfavorable prognosis, HSCT is recommended. ${ }^{14,17-19}$

\begin{tabular}{c|c|c|c}
\hline HSCT indication & $\begin{array}{c}\text { Allogeneic } \\
\text { HSCT }\end{array}$ & $\begin{array}{c}\text { Autologous } \\
\text { HSCT }\end{array}$ & Notes \\
\hline $\begin{array}{c}\text { JMML (patients with NF1, somatic PTPN11 } \\
\text { Nutation, KRAS, most patients with somatic } \\
\text { NRAS mutation and patients with no identified } \\
\text { mutation) }\end{array}$ & $\mathrm{S}$ & $\mathrm{N}$ & $\begin{array}{c}\text { In some patients with germline mutation } \\
\text { of NRAS, mainly with normal fetal } \\
\text { hemoglobin and without significant } \\
\text { thrombocytopenia, long-term survival } \\
\text { without HSCT has been observed. }\end{array}$ \\
\hline JMML (patients with CBL germline mutation) & $\mathrm{N}$ & $\mathrm{N}$ & $\begin{array}{c}\text { Most patients have spontaneous } \\
\text { resolution. Allogeneic HSCT should be } \\
\text { assessed if chromosomal changes or } \\
\text { disease progression occur. }\end{array}$ \\
\hline
\end{tabular}

\section{S: Standard of care}

C: Standard of care, clinical evidence available

$\mathrm{R}$ : Standard of care, rare indication

D: Developmental

$\mathrm{N}$ : Not generally recommended

\section{REFERENCES}

1.LocatelliF, NiemeyerCM. How Itreatjuvenilemyelomonocytic leukemia. Blood. 2015;125(7):10831090. doi:10.1182/blood-2014-08-550483.

2. Niemeyer CM. JMML genomics and decisions. Hematology Am Soc Hematol Educ Program. 2018;2018(1):307-312. doi:10.1182/asheducation-2018.1.307.

3. Niemeyer CM, Flotho C. Juvenile myelomonocytic leukemia: who's the driver at the wheel?. Blood. 2019;133(10):1060-1070. doi:10.1182/ blood-2018-11-844688

4. Niemeyer CM. RAS diseases in children. Haematologica. 2014;99(11):1653-1662. doi:10.3324/ haematol.2014.114595.
5. Locatelli F, Nöllke P, Zecca M, et al. Hematopoietic stem cell transplantation (HSCT) in children with juvenile myelomonocytic leukemia (JMML): results of the EWOG-MDS/EBMT trial. Blood. 2005;105(1):410-419. doi:10.1182/ blood-2004-05-1944.

6. Locatelli F, Crotta A, Ruggeri A, et al. Analysis of risk factors influencing outcomes after cord blood transplantation in children with juvenile myelomonocytic leukemia: a EUROCORD, EBMT, EWOG-MDS, CIBMTR study. Blood. 2013;122(12):2135-2141. doi:10.1182/ blood-2013-03-491589.

7. Ding $L$, Zhu H, Han DM, et al. Clinical study on treatment of juvenile myelomonocytic leuke- 
mia with haploidentical hematopoietic stem cell transplantation. Zhongguo Shi Yan Xue Ye Xue Za Zhi. 2017;25(5):1524-1527. doi:10.7534/j. issn.1009-2137.2017.05.043.

8. Dvorak CC, Satwani P, Stieglitz E, et al. Disease burden and conditioning regimens in ASCT1221, a randomized phase II trial in children with juvenile myelomonocytic leukemia: A Children's Oncology Group study. Pediatr Blood Cancer. 2018;65(7):e27034. doi:10.1002/pbc.27034.

9. Yoshida N, Sakaguchi H, Yabe M, et al. Clinical Outcomes after Allogeneic Hematopoietic Stem Cell Transplantation in Children with Juvenile Myelomonocytic Leukemia: A Report from the Japan Society for Hematopoietic Cell Transplantation. Biol Blood Marrow Transplant. 2020;26(5):902910. doi:10.1016/j.bbmt.2019.11.029.

10. Wajid MA, Gupta AK, Das G, et al. Outcomes of juvenile myelomonocytic leukemia patients after sequential therapy with cytarabine and 6-mercaptopurine. Pediatr Hematol Oncol. 2020;37(7):573-581. doi:10.1080/08880018.202 0.1767244 .

11. Cseh A, Niemeyer CM, Yoshimi A, et al. Bridging to transplant with azacitidine in juvenile myelomonocytic leukemia: a retrospective analysis of the EWOG-MDS study group. Blood. 2015;125(14):2311-2313. doi:10.1182/ blood-2015-01-619734.

12. Marcu A, Colita A, Radu LE, et al. Single-Center Experience With Epigenetic Treatment for Juvenile Myelomonocytic Leukemia. Front Oncol. 2020;10:484. doi:10.3389/fonc.2020.00484.

13 Flotho C, Sommer S, Lübbert M. DNA-hypomethylating agents as epigenetic therapy before and after allogeneic hematopoietic stem cell transplantation in myelodysplastic syndromes and juvenile myelomonocytic leukemia. Semin Cancer Biol. 2018;51:68-79. doi:10.1016/j. semcancer.2017.10.011

14. Hasle $\mathrm{H}$, Niemeyer CM, Chessells JM, et al. A pediatric approach to the WHO classification of myelodysplastic and myeloproliferative diseases. Leukemia. 2003;17(2):277-282. doi:10.1038/ sj.leu.2402765.

15. Tsurusawa M, Manabe A, Hayashi Y, et al. Therapy-related myelodysplastic syndrome in childhood: a retrospective study of 36 patients in Japan. Leuk Res. 2005;29(6):625-632. doi:10.1016/j. leukres.2004.11.018.

16 Occhipinti E, Correa H, Yu L, Craver R. Inclusion of secondary chronic myelomonocytic leukemia and myeloproliferative disease, unclassifiable, in classification of pediatric myeloproliferative disorders.J Pediatr Hematol Oncol.2006;28(10):700701. doi:10.1097/01.mph.0000243643.13369.63.

17. Jaing TH, Hung IJ, Chen SH, et al. Successful transplantation of ethnically mismatched cord blood in a boy with atypical chronic myeloid leukemia. Int J Hematol. 2013;97(1):144-146. doi:10.1007/s12185-012-1251-2.

18. Freedman JL, Desai AV, Bailey LC, et al. Atypical Chronic Myeloid Leukemia in Two Pediatric Patients. Pediatr Blood Cancer. 2016;63(1):156-159. doi:10.1002/pbc.25694.

19. Gotlib J. How I treat atypical chronic myeloid leukemia. Blood. 2017;129(7):838-845. doi:10.1182/blood-2016-08-693630. 